\title{
Uji efek ekstrak daun dewa (Gyanurasegetum [Lour]. Merr) terhadap masa penyembuhan luka insisi kulit kelinci (Oryctolaguscuniculus)
}

\author{
${ }^{1}$ Aaron \\ ${ }^{2}$ Henoch Awaloei \\ ${ }^{2}$ Jane Wuisan
}

\author{
${ }^{1}$ Kandidat Skripsi Fakultas Kedokteran Universitas Sam Ratulangi Manado \\ ${ }^{2}$ Bagian Farmakologi dan Terapi Fakultas Kedokteran Universitas Sam Ratulangi Manado \\ E-mail: aaronalfred110111080@gmail.com
}

\begin{abstract}
Marsh fleabane (Gynurasegetum [Lour].Merr.) is one of the medicinal plants used by the public as an anti-septic to accelerate wound healing. The contents of Marsh fleabane that could accelerate wound healing are flavonoids, saponins, and atsiri oil. This study aimed to determine the effect of Marsh fleabane extract on wound healing incision of rabbit skin. This was an experimental study. This study was conducted in the Laboratory of Pharmacology and Therapeutics Faculty of Medicine, University of Sam Ratulangi. Samples were 3 rabbits. Incised wounds of $4 \mathrm{~cm}$ length and $2 \mathrm{~mm}$ depth were made on the rabbits' left and right backs. The wounds on the left backs were given Marsh fleabane extract, meanwhile the wounds on the right backs were not treated. The results showed that the wound healing process of the incised wounds treated with Marsh fleabane extract was faster compared to the incised wounds without treatment. Conclusion: Marsh fleabane extract could accelerate the wound healing process of rabbit incised wound.
\end{abstract}

Keywords: marsh fleabane, incision wound healing

\begin{abstract}
Abstrak: Daun dewa (Gyanurasegetum [Lour].Merr.) merupakan salah satu tanaman berkhasiat yang biasa digunakan oleh masyarakat sebagai obat anti septik dan mempercepat penyembuhan luka. Kandungan yang terkandung dalam daun dewa yang dipercaya dapat mempercepat penyembuhan luka yaitu flavonoid, saponin, dan minyak atsiri. Penelitian ini bertujuan untuk mengetahui uji efek ekstrak daun dewa terhadap penyembuhan luka insisi pada kulit kelinci. Metode penelitian yang digunakan ialah rancangan eksperimental. Penelitian ini dilaksanakan di Laboratorium Farmakologi dan Terapi Fakultas Kedokteran Universitas Sam Ratulangi. Sampel yang digunakan berjumlah 3 ekor kelinci yang masingmasing punggung kiri dan kanannya diberi luka insisi sepanjang $4 \mathrm{~cm}$ dan kedalaman $2 \mathrm{~mm}$. Luka pada punggung sebelah kiri diberikan ekstrak daun dewa sedangkan luka pada punggung bagian kanan tidak diberikan ekstrak daun dewa. Hasil penelitian memperlihatkan bahwa masa penyembuhan luka insisi kulit kelinci yang diberikan ekstrak daun dewa lebih singkat dibandingkan dengan luka insisi kulit kelinci yang tidak diberikan ekstrak daun dewa. Simpulan: Ekstrak daun dewa berefek terhadap penyembuhan luka insisi kulit kelinci.

Kata kunci: daun dewa, penyembuhan luka insisi
\end{abstract}

Bangsa Indonesia telah lama mengenal dan menggunakan tanaman berkhasiat sebagai obat untuk menanggulangi masalah kesehatan. Pengetahuan tentang tanaman berkhasiat obat berdasarkan pengalaman dan keterampilan yang diwariskan secara turun temurun. ${ }^{1}$ Di Indonesia terdapat 30.000 jenis tumbuhan dan 940 jenis diantaranya merupakan tumbuhan berkhasiat yang digunakan sebagai obat untuk menanggulangi masalah kesehatan. ${ }^{2}$

Data dari Kepolisian Republik 
Indonesia tahun 2009 menyebutkan, Indonesia merupakan salah satu negara yang memiliki tingkat kecelakaan lalu lintas yang cukup tinggi. Sepanjang tahun tersebut setidaknya 57.726 kasus kecelakaan di jalan raya yang dapat menyebabkan luka ringan dan luka berat. ${ }^{3}$ Luka adalah hilang atau rusaknya sebagian jaringan tubuh. Keadaan ini dapat disebabkan oleh trauma, benda tajam, benda tumpul, perubahan suhu, zat kimia, atau gigitan hewan. ${ }^{4}$

Salah satu tanaman berkhasiat yang dapat digunakan sebagai antiseptik yaitu daun dewa. Kandungan yang diduga terkandung dalam daun dewa yang dapat berperan sebagai antiseptik dan mempercepat penyembuhan luka yaitu flavonoid, saponin, tanin dan minyak atsiri. ${ }^{5}$ Selain berkhasiat sebagai antiseptik dan mempercepat penyembuhan luka, daun dewa juga dapat menurunkan kadar glukosa dalam darah, menurunkan kadar kolesterol dalam darah, menghilangkan nyeri persendian akibat asam urat, dan sebagai antipiretik. $^{6} \quad$ Penggunaan tumbuhan berkhasiat obat secara umum lebih aman dari pada penggunaan obat sintetik karena memiliki efek samping yang relatif sedikit jika digunakan secara tepat, yang meliputi kebenaran bahan, ketepatan dosis, ketepatan waktu penggunaan, ketepatan cara penggunaan, tanpa penyalahgunaan dan ketepatan pemilihan untuk indikasi tertentu. $^{7}$

Berdasarkan hal di atas penulis tertarik untuk melakukan penelitian tentang uji efek ekstrak daun dewa (Gyanura segetum [Lour].Merr) terhadap penyembuhan luka insisi pada kulit kelinci (Oryctolagus cuniculus).

\section{BAHAN DAN METODE PENELITIAN}

Penelitian ini merupakan penelitian eksperimental dan dilaksanakan di Laboratorium Farmakologi dan Terapi Fakultas Kedokteran Universitas Sam Ratulangi. Sampel penelitian ini yaitu kelinci sebanyak 3 ekor dengan berat 1.500 g. Masing masing kelinci dibuat luka insisi pada bagian punggung kiri dan punggung kanan kelinci sepanjang $4 \mathrm{~cm}$ dengan kedalaman $2 \mathrm{~mm}$. pada luka insisi bagian kiri punggung kelinci di berikan ekstrak daun dewa sedangkan bagian kanan punggung kelinci tidak diberikan perlakuan. Setelah itu luka ditutup dengan menggunakan kasa steril dan diamati setiap hari pada sore hari selama 2 minggu. Variabel penelitian ini yaitu daun dewa dan penyembuhan luka insisi kulit kelinci. Hasil penelitian disajikan dalam bentuk tabel dan grafik perkembangan penyembuhan luka insisi pada kulit kelinci kontrol dan perlakuan dengan kriteria penilaian panjang luka.

\section{HASIL PENELITIAN DAN BAHASAN}

Hasil penelitian mengenai uji efek ekstrak daun dewa (Gyanura segetum [Lour].Merr) terhadap penyembuhan luka insisi pada kulit kelinci (Oryctolagus cuniculus) didistribusikan dalam bentuk tabel dan grafik berdasarkan pengamatan penyembuhan luka insisi kulit kelinci A, B, dan C.

Tabel 1. Pengamatan penyembuhan luka insisi kulit kelinci A

\begin{tabular}{ccl}
\hline $\begin{array}{c}\text { Hari ke- } \\
\text { (kontrol) }\end{array}$ & $\begin{array}{c}\text { Kiri } \\
\text { (perlakuan) }\end{array}$ & Kanan \\
\hline 0 & $4,0 \mathrm{~cm}$ & $4,0 \mathrm{~cm}$ \\
1 & $4,0 \mathrm{~cm}$ & $4,0 \mathrm{~cm}$ \\
2 & $3,8 \mathrm{~cm}$ & $3,9 \mathrm{~cm}$ \\
3 & $3,5 \mathrm{~cm}$ & $3,6 \mathrm{~cm}$ \\
4 & $3,0 \mathrm{~cm}$ & $3,4 \mathrm{~cm}$ \\
5 & $2,8 \mathrm{~cm}$ & $3,2 \mathrm{~cm}$ \\
6 & $2,4 \mathrm{~cm}$ & $3,1 \mathrm{~cm}$ \\
7 & $2,3 \mathrm{~cm}$ & $2,9 \mathrm{~cm}$ \\
8 & $2,2 \mathrm{~cm}$ & $2,6 \mathrm{~cm}$ \\
9 & $2,0 \mathrm{~cm}$ & $2,4 \mathrm{c}$ \\
10 & $1,8 \mathrm{~cm}$ & $2,0 \mathrm{~cm}$ \\
11 & $1,6 \mathrm{~cm}$ & $1,7 \mathrm{~cm}$ \\
12 & $1,2 \mathrm{~cm}$ & $1,4 \mathrm{~cm}$ \\
13 & $0,7 \mathrm{~cm}$ & $1,0 \mathrm{~cm}$ \\
14 & $0 \mathrm{~cm}$ & $0.6 \mathrm{~cm}$ \\
\hline
\end{tabular}

Keterangan:

Kiri: Luka yang diberi ekstrak daun dewa Kanan: Luka tanpa perlakuan 


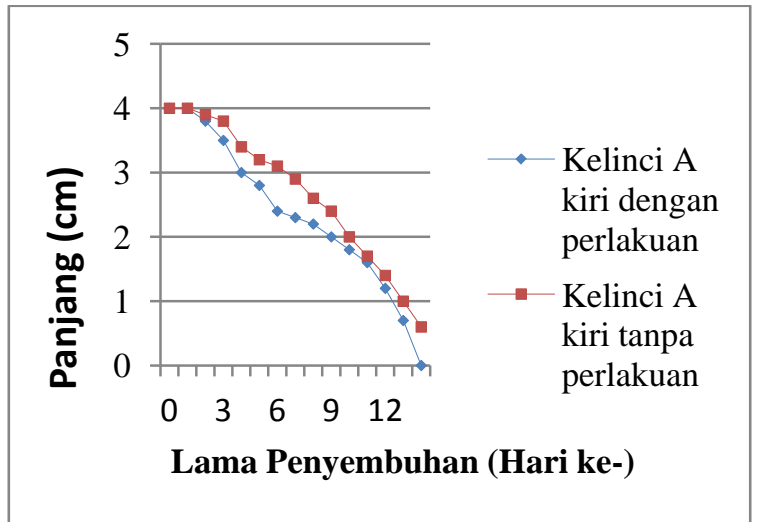

Gambar 1. Grafik perkembangan penyembuhan luka insisi kulit kelinci A dengan kriteria penilaian panjang luka

Pemeriksaan makroskopis pada hari ke-3 terlihat luka yang diberi perlakuan sudah hampir sepenuhnya menyatu. Hal tersebut sesuai dengan teori inflamasi yang dijelaskan bahwa fase inflamasi sudah mulai sejak 24 jam sesudah jejas, sel-sel fibroblas dan endotel pembuluh darah mulai berproliferasi membentuk jaringan granulasi sehingga penyatuan kulit terlihat lebih cepat. $^{8}$

Pemeriksaan makroskopis pada hari ke-7 terlihat luka yang diberi ekstrak daun dewa tampak sudah menyatu, lebih kecil dan terdapat kerak yang menutup proses ini dapat terlihat pada gambar 9,11 dan 13 sedangkan pada luka yang tidak diberikan apapun tampak luka belum menyatu secara merata, lebih panjang, mengerut dan dibeberapa bagian belum tertutup kerak yang merupakan salah proses penyembuhan proses ini dapat dilihat pada gambar 10, 12 dan 14.

Pada hari ke-7 terjadi fase proliferasi, dimana substansi dasar, serabut - serabut kolagen serta pembuluh darah baru mulai menginfiltrasi luka. Begitu kolagen terbentuk maka terjadi peningkatan yang cepat pada kekuatan regangan luka. ${ }^{8}$

Pemeriksaan makroskopis pada hari ke-14 terlihat luka yang diberi ekstrak daun dewa lebih kecil dan sudah tertutup sempurna, proses ini dapat dilihat pada gambar 15,17 dan 19. Sedangkan pada luka yang tidak diberikan ekstrak daun dewa tampak luka lebih besar, dan belum menutup sempurna, proses ini dapat dilihat pada gambar 16, 18 dan 20. Pada saat ini terjadi fase remodelling, dimana kolagen yang telah terbentuk akan menyatu, menekan pembuluh darah dalam penyembuhan luka, sehingga bekas luka menjadi rata dan tipis. ${ }^{8}$

Pada luka insisi kulit kelinci yang diberi ekstrak daun dewa lebih cepat penyembuhannya dibanding dengan luka yang tidak diberikan apapun. Hal ini disebabkan karena ekstrak daun dewa mengandung minyak atsiri dan senyawa flavonoid yang dapat mempercepat proses penyembuhan luka.,

Tabel 2. Pengamatan penyembuhan luka insisi kulit kelinci B

\begin{tabular}{ccc}
\hline $\begin{array}{c}\text { Hari ke- } \\
\text { (kontrol) }\end{array}$ & Kiri (perlakuan) Kanan \\
\hline 0 & $4,0 \mathrm{~cm}$ & $4,0 \mathrm{~cm}$ \\
1 & $4,0 \mathrm{~cm}$ & $4,0 \mathrm{~cm}$ \\
2 & $3,2 \mathrm{~cm}$ & $2,5 \mathrm{~cm}$ \\
3 & $2,9 \mathrm{~cm}$ & $2,2 \mathrm{~cm}$ \\
4 & $2,6 \mathrm{~cm}$ & $2,0 \mathrm{~cm}$ \\
5 & $2,4 \mathrm{~cm}$ & $1,9 \mathrm{~cm}$ \\
6 & $2,0 \mathrm{~cm}$ & $1,9 \mathrm{~cm}$ \\
7 & $1,8 \mathrm{~cm}$ & $1,7 \mathrm{~cm}$ \\
8 & $1,6 \mathrm{~cm}$ & $1,5 \mathrm{~cm}$ \\
9 & $1,2 \mathrm{~cm}$ & $1,3 \mathrm{~cm}$ \\
10 & $1,0 \mathrm{~cm}$ & $1,1 \mathrm{~cm}$ \\
11 & $0,9 \mathrm{~cm}$ & $0,9 \mathrm{~cm}$ \\
12 & $0,7 \mathrm{~cm}$ & $0,7 \mathrm{~cm}$ \\
13 & $0,6 \mathrm{~cm}$ & $0,6 \mathrm{~cm}$ \\
14 & $0,4 \mathrm{~cm}$ & $0.5 \mathrm{~cm}$ \\
\hline
\end{tabular}

Keterangan:

Kiri: Luka yang diberi ekstrak daun dewa Kanan: Luka tanpa perlakuan

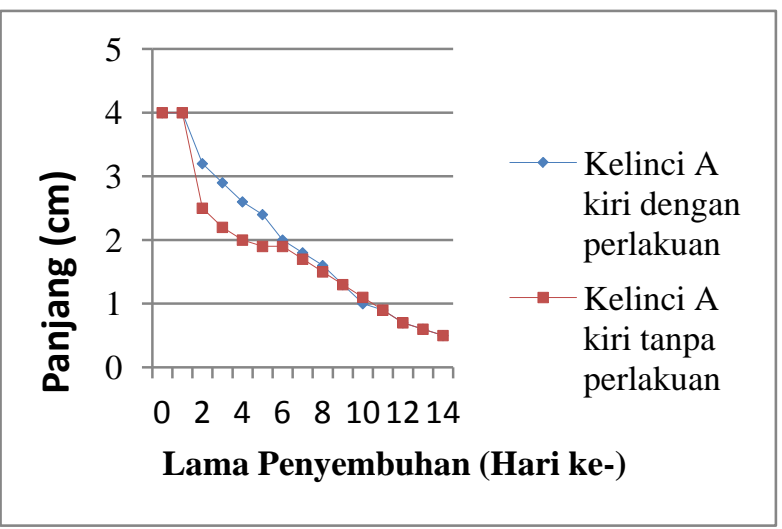

Gambar 2. Grafik perkembangan penyembuhan luka insisi kulit kelinci A dengan kriteria lama penyembuhan 
Tabel 3. pengamatan penyembuhan luka insisi kulit kelinci C

\begin{tabular}{ccc}
\hline $\begin{array}{c}\text { Hari ke- } \\
\text { (kontrol) }\end{array}$ & Kiri (perlakuan) Kanan \\
\hline 0 & $4,0 \mathrm{~cm}$ & $4,0 \mathrm{~cm}$ \\
1 & $4,0 \mathrm{~cm}$ & $4,0 \mathrm{~cm}$ \\
2 & $3,5 \mathrm{~cm}$ & $3,3 \mathrm{~cm}$ \\
3 & $3,0 \mathrm{~cm}$ & $3,0 \mathrm{~cm}$ \\
4 & $2,8 \mathrm{~cm}$ & $2,9 \mathrm{~cm}$ \\
5 & $2,5 \mathrm{~cm}$ & $2,7 \mathrm{~cm}$ \\
6 & $2,0 \mathrm{~cm}$ & $2,5 \mathrm{~cm}$ \\
7 & $1,9 \mathrm{~cm}$ & $2,3 \mathrm{~cm}$ \\
8 & $1,6 \mathrm{~cm}$ & $2,1 \mathrm{~cm}$ \\
9 & $1,2 \mathrm{~cm}$ & $1,8 \mathrm{~cm}$ \\
10 & $0,9 \mathrm{~cm}$ & $1,5 \mathrm{~cm}$ \\
11 & $0,7 \mathrm{~cm}$ & $1,3 \mathrm{~cm}$ \\
12 & $0,3 \mathrm{~cm}$ & $0,9 \mathrm{~cm}$ \\
13 & $0,0 \mathrm{~cm}$ & $0,6 \mathrm{~cm}$ \\
14 & $0,0 \mathrm{~cm}$ & $0.0 \mathrm{~cm}$ \\
\hline
\end{tabular}

Keterangan:

Kiri: Luka yang diberi ekstrak daun dewa Kanan: Luka tanpa perlakuan

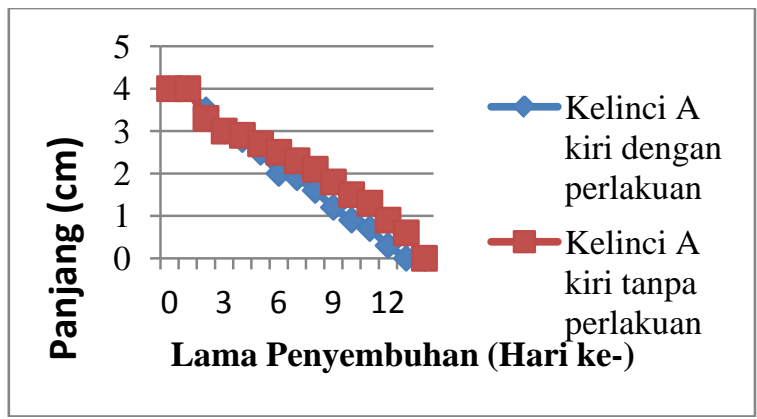

Gambar 3. Grafik perkembangan penyembuhan luka insisi kulit kelinci A dengan kriteria penilaian panjang luka an lama penyembuhan

\section{SIMPULAN}

Pemberian ekstrak daun dewa berefek mempercepat penyembuhan luka insisi pada kulit kelinci.

\section{SARAN}

1. Perlu dilakukan penelitian dengan subjek yang lebih banyak.

2. Perlu dilakukan pemeriksaan luka secara mikroskopis untuk melihat efek ekstrak daun dewa terhadap penyembuhan luka.

\section{UCAPAN TERIMA KASIH}

Ucapan terima kasih disampaikan pada dr. P. M. Wowor, MKes, SpFK, dr. C. Mambo, MSc serta seluruh pihak yang baik secara langsung maupun tidak langsung telah menumbuhkan ide atau gagasan dalam pemikiran penulis sehingga dapat menyelesaikan artikel ini.

\section{DAFTAR PUSTAKA}

1. Sukandar. Trend dan Paradigma Dunia Farmasi: Industri Klinik Teknologi Kesehatan Bandung. Bandung: Institut Teknologi Bandung, 2006; p. 2.

2. Masyhud. Lokakarya Nasional Tanaman Obat Di Indonesia. 22 juli 2010 [diakses pada: 17 oktober 2014]. Diunduh dari: http://www.dephut.go.id/index.php/ne ws/details/7043.

3. Afidah, Susilaningrum. Pola tingkat keparahan korban kecelakaan lalu lintas dengan menggunakan regresi logistik multinomal (Studi Kasus: Kecelakaan Lalu Lintas di Surabaya). Surabaya: Fakultas Matematika dan Ilmu Alam, Institut Teknologi Surabaya, 2010; p.13.

4. Hasibuan LY, Hardisiswo, Soedjana, Bisono. Luka. In: Sjamsuhidajat, de Jong. Buku Ajar Ilmu bedah (3rd ed). Jakarta: EGC, 2010. p. 95-7.

5. Nuraini DN. Aneka Daun Berkhasiat untuk Obat. Yogyakarta: Gava Media, 2014; p. 52.

6. Herliana. Penyakit Asam Urat kandas berkat herbal. Jakarta: Fmedia, 2013; p. 39-40.

7. Kumala Sari LOR. Pemanfaatan Obat Tradisional dengan Pertimbangan Manfaat dan Keamanannya. J. Farmasi[internet].2006 (diakses pada: 10 November 2012). Diunduh dari: http://journal.ui.ac.id/index.php/mik/a rticle/download/1155/1062

8. Cruse PJE, Mcphedran NT. In: Sabiston D. Buku Ajar Ilmu Bedah. Jakarta: EGC, 1995; p. 148-50.

9. Rusli MS. Sukses Memprokduksi Minyak Atsiri. Jakarta: PT Agro Media Pustaka; 2010. p. 3-4

10.Winarsi H. Antikosidan Alami dan Radikal Bebas. Yogyakarta: Kanisius, 2007; p. 186. 